\title{
Expert views on strategies to increase water resilience: evidence from a global survey
}

\author{
Lucy Rodina $^{1}$ and Kai M.A. Chan ${ }^{1}$
}

\begin{abstract}
Scholars and policy-makers are advocating for increasing the resilience of water systems, both social and biophysical, to climate change impacts, and global environmental change more broadly. But what is "water resilience," and what does it imply for water resources management and water governance? Generally, water resilience may include ecological aspects of water quality or flood mitigation, engineered infrastructure to ensure safe and reliable water supply and to mitigate floods, and the socially inclusive and equitable governance of these systems. Following this, our goal was twofold: (1) explore and draw out a comprehensive set of water resource management strategies across sectors that are likely to contribute to increased resilience, and (2) investigate whether disciplinary divides are indeed a barrier toward convergence around key water resilience actions. To address these two gaps, we drew on a survey of experts in resilience and various aspects of water management and governance $(n=420)$, and aimed to synthesize their views on the specific strategies that can help enhance water resilience. Specifically, we surveyed experts across various water domains from ecosystem management to drought and flood management. Overall, we found that while debates about how to theorize or operationalize resilience in relation to different systems - social or biophysical - may be unresolved, there is considerable convergence among various experts about which actions are likely to make water systems more resilient to increasing risks and uncertainties. The most widely agreed upon strategies for building water resilience revolve around improved ecosystem health, integration across scales, and adaptation to change.
\end{abstract}

Key Words: drought; flood; water resilience; water resource management; water security; watershed governance

\section{INTRODUCTION}

Global environmental change and climate change impacts are affecting watersheds and water supply systems worldwide (Steffen et al. 2011, Ferguson et al. 2013, Rockström et al. 2014a). Cities and communities across the world are facing growing water security risks, more frequent or intense flooding, or increasing stress on eco-hydrological systems, such as rivers, wetlands, or groundwater. There is growing evidence that conventional water resource management paradigms are not sufficiently equipped to respond to surprise or uncertainty in the hydrologic cycle (Huitema et al. 2009, Wong and Brown 2009, Huntjens et al. 2012, Bell 2015). Consider the case of Cape Town, South Africa, which recently experienced one of its worst droughts in history. In late 2017, extremely low dam levels, together with a series of governance challenges, led to the possibility of Cape Town running out of water in 2018 (at the time of writing, "Day Zero" had been pushed back indefinitely) - an example that is not unique to Cape Town, as several other major cities are facing similar challenges (Welch 2018). Overall, according to the UN World Water (2015) report, most water systems around the world are not resilient to increasing risks, and many of them are not able to provide basic services in many areas, particularly in the global south.

In light of these challenges, many scholars have highlighted the need to transform water resource management and governance paradigms toward resilience. These contributions include Milly et al.'s (2008) seminal piece on accepting nonstationarity as a principle in water resource management, Rockström et al. (2014b), who argue for moving beyond blue-water management to incorporate precipitation, Dunn et al. (2016), who theorize urban water practices through the lens of complexity, and Ferguson et al. (2013), who propose a framework to diagnose and navigate transformative change in urban water systems. According to these and other authors, transformation is needed to increase the ability of water systems, as well as water institutions, to deal with hydrologic uncertainty and unpredictability, and to increase connectivity across scales - in other words, to increase water resilience to various complex and emerging stressors.

However, building resilience in water systems (be they ecological, engineered, or social) is still not well understood, in part due to a lack of guidance - theoretical or practical - with respect to what constitutes resilience in water systems or how it may be achieved. A major contributor to this challenge is the fact that water systems themselves are complex, highly fragmented, and typically compartmentalized across disconnected sectors - e.g., supply and demand management, wastewater, or stormwater management. Further, engineered water systems worldwide are embedded in infrastructural legacies and design paradigms that have historically been inflexible and slow to adapt to change (Brown et al. 2009, White 2010, Bell et al. 2017). While efforts have been made to rethink water systems in more integrated and adaptive ways (e.g., through the concepts of integrated water resource management [Biswas 2009] or water-sensitive urban design [Wong and Brown 2009]), disciplinary legacies and sectoral fragmentation in the water sector are persistent and difficult to overcome (Rodina 2019b).

Resilience - commonly understood as the ability of systems (social or biophysical) to withstand or cope with stressors while continuing to maintain key functions or structures (Folke 2016) - suffers from similar limitations. Namely, the multiplicity of epistemological, empirical, and applied aspects poses tremendous challenges for operationalizing resilience in different contexts 
(Olsson et al. 2015). In the context of water systems, various definitions of resilience are being used: for example, engineering resilience, measuring the attributes of engineered water systems and their ability to bounce back from disruptions (e.g., Shin et al. 2018); ecological resilience, focusing on the capacity of ecohydrological systems to cope with stress (e.g., Falkenmark and Rockström 2010); or community resilience, focusing on the ability of society to cope with water stressors or risks (e.g., D'Odorico et al. 2010). Applying different resilience definitions ultimately leads to vastly different notions of what systems should be made resilient and how (Rodina 2019a). Overall, resilience thinking in relation to water has been applied in patchy ways, without significant theoretical or empirical convergence around definitions or characteristics of resilient water systems (Rodina 2019b). However, it remains unclear whether these disciplinary divides actually inhibit integrative thinking on water resilience.

Further, outside of ongoing epistemological and methodological debates in the resilience scholarship, there is a limited shared understanding or guidance on which specific water management practices and governance arrangements can increase resilience in water systems, whether in general senses or in specific water systems. A growing body of work is increasingly arguing for more integrative ways of moving toward water resilience to encompass the various aspects of water systems (social, infrastructural, or ecological) (Rodina 2019b). There is, therefore, a clear need to study water resilience in a broader sense, beyond the silos of conventional compartmentalization in the water sector. While several authors have suggested enabling factors for increasing resilience in specific domains of water management (e.g., Rockström et al. 2014b, Johannessen and Wamsler 2017), to date there has not been a comprehensive overview of the strategies that can help increase resilience in water systems. As a result, there is a lack of knowledge about precisely how to increase water resilience in a comprehensive sense that encompasses the hydrologic, built, and social dimensions of water systems.

Our goal is twofold: (1) to explore and draw out a comprehensive set of water resource management strategies across sectors that are likely to contribute to increased resilience, and (2) to investigate whether disciplinary divides are indeed a barrier toward convergence around key water resilience actions. To address these two gaps, we surveyed experts across various water domains, from ecosystem management to drought and flood management. Specifically, we asked to what extent experts from various resilience perspectives align or diverge on the strategies that are most important for building water resilience. Ultimately, we aim to explore the commonalities and differences in expert perceptions of water resilience strategies by investigating the prominence (or lack thereof) of disciplinary drivers. This approach helps in investigating the effect of disciplinary divides in resilience thinking on the resilience building strategies that experts are more likely to favor, and to better understand the barriers and opportunities for a more integrative approach to water resilience.

To capture diverse water systems, we surveyed the views of experts in various domains of water management (e.g., stormwater management, water resource management, water and sanitation) who were familiar with resilience as a concept or a theory. We conducted an online survey $(n=420)$ by recruiting authors of
English language academic publications on these topics, who were identified through a systematic scoping review (documented in Rodina 2019b). Survey participants were asked to respond to a range of resilience questions and to rate a series of resilience building strategies. We investigate how experts rated the strategies, and based on their choice of resilience definitions (used as proxies for different disciplinary understandings of resilience), we analyze the degree to which support for various types of strategies is driven by disciplinary traditions in the resilience scholarship. In other words, the analysis aims to show to what degree those who selected a particular definition of resilience favored certain strategies over others. Using principal component analysis, we identify several key components, or subsets of closely related resilience building strategies, that we then elaborate. In addition, we discuss the highest rated resilience building strategies to provide insights on the best practices for resilience, according to the surveyed experts. The evidence suggests, first, that despite the diversity of water fields and resilience orientations, there is overwhelmingly strong support for most of the strategies in this survey, which suggests crosscutting agreement that most of these strategies are important and are needed for enhancing water resilience. Second, the results also indicate that managing for ecosystem health is the highest order of priority for increased water resilience.

\section{WHAT DO WE (NOT) KNOW ABOUT WATER RESILIENCE?}

A resilience-informed approach to water resource management and governance involves a range of principles. Rodina's (2019b) recent study systematically investigated the literature that draws on resilience framings in relation to various aspects of water, and concluded that, overall, approaches to water resilience are predominantly discordant, with limited theoretical and empirical integration. For example, resilience is used in the context of engineered water systems, such as water reticulation systems (e.g., Fowler et al. 2003), ecosystems such as rivers or watersheds (e.g., Falkenmark and Rockstrom 2010), communities (e.g., D'Odorico et al. 2010), or water institutions (e.g., Green et al. 2013). Further, the literature on water resilience puts forward a large number of complex and diverse propositions that tend to draw on many different aspects, scales, characteristics, or types of water systems, be they biophysical or social (Rodina 2019b). These include embracing uncertainty about future hydrologic variability, or a holistic understanding of the hydrological cycle to include runoff, green water, precipitation, etc. Others promote flexible, inclusive, open, and adaptive cogovernance institutional models that allow for effective deliberation with stakeholders, and learning and policy experimentation (Gunderson et al. 2006, Baker et al. 2009, PahlWostl et al. 2010, Berkes et al. 2012, Cosens and Williams 2012, Rockström et al. 2014b). In the context of urban water, for example, Jabareen (2013) defines resilient cities as those in which governance is able to quickly restore basic services and resume social, institutional, and economic activities after a disaster. Others define water-resilient cities as being able to manage floods and water scarcity through a combination of measures to reduce exposure and vulnerability to those hazards, and to embrace multifunctional use of land or integrated upstream and downstream water management (White 2010). 


\section{Resilience in water resource management and governance}

Water resilience is increasingly used in relation to social systems, particularly in the context of water resource management and governance (Rodina 2019b). We refer to water governance as the range of water management practices and institutional arrangements at various aspects of the water cycle-flood risk management, drought management, water resource management, etc. Water governance is typically defined as the political, organizational, and administrative processes through which communities articulate their interests, their input is absorbed, decisions are made and implemented, and decision-makers are held accountable for the development and management of water resources and delivery of water services (Bakker and Cameron 2005). We add to this definition the specific management practices in different water sectors (e.g., supply diversification, flood risk management) because they form a key part of how water resilience is operationalized. In addition, making choices about how to operationalize water resilience is ultimately a governance process.

With respect to water governance, several authors have argued that polycentric governance is important for enhancing resilience. Polycentric governance implies moving away from hierarchical, top-down, often state-led governance of water to include a wider range of actors from civil society, community-based organizations, and local forms of governance that share authority and responsibilities in water management (Galaz 2005, Pahl-Wost et al. 2012, Bakker and Morinville 2013, Rijke et al. 2013). Such "independent but coordinated centers of authority" are theorized as better able to respond to environmental problems at the scale at which they occur (Huntjens et al. 2012). One key aspect of this shift is decentralization of governance, whereby authority to make decisions and take action is devolved to scales that are considered a better fit to the scale of the issues being addressed (also known as the subsidiarity principle). The debate about the merits and disadvantages of centralized and decentralized forms of governance in the water sector is ongoing. Some authors have argued that hierarchies are better able to solve simple problems and to mobilize and coordinate action; however, they tend to have low capacity to solve complex problems and can sometimes result in illegitimate and unjust outcomes (Rijke et al. 2013).

On the other hand, others have argued that decentralized approaches are better able to solve complex problems by involving a wider diversity of stakeholders and, therefore, a wider diversity of knowledge, as well as the opportunities to learn through strategic collaboration (Krievins et al. 2015). However, in some cases, decentralized and poorly coordinated water systems have resulted in unequal outcomes, as in the case of the highly fragmented water governance landscape in Canada, which has yielded inequality in local capacity to manage water effectively (Dunn et al. 2017). Resilience scholars also argue that to enhance the resilience, as well as the transformative capacity, of urban water systems, there is a need for a mix of centralized and decentralized governance forms, as well as a mix of formal and informal institutions (Rijke et al. 2013).

Adaptive governance and adaptive comanagement have been proposed by many scholars as necessary for dealing with social and environmental complexity and unpredictability (Huitema et al. 2009). The adaptive aspect here typically refers to the ability of decision-makers and stakeholders to adapt their approaches through learning and experimentation in response to specific ecosystem feedbacks or stressors (Huntjens et al. 2012, PahlWostl and Knieper 2014). In addition, flexibility and diversity in response options have been suggested as principles that foster resilience to uncertain and variable water futures. This includes using multiple and diverse sources of water (e.g., surface water, groundwater), reclaiming and recycling water for nonpotable uses, such as using rainwater for gardening and toilet flushing, which in turn requires new infrastructures and regulations to balance public health and other concerns.

In the context of natural resource management, flexibility and diversity of response options have been proposed as key resilienceenhancing strategies because they allow the social system to adaptively respond to change (Schluter and Pahl-Wostl 2007). These principles, however, may not be applicable in all contexts. For example, Srinivasan et al. (2013) demonstrated that while peri-urban households (away from the periphery of cities) may have flexibility and diversity in resource access through connection to the municipal piped systems and through their own private wells, during times of scarcity this does not necessarily make the water system more resilient. Drawing on underground water supplies - especially when unregulated-may lessen the resilience of water resources for the whole urban area (Srinivasan et al. 2013). In sum, while polycentric governance with effective vertical and horizontal distribution of authority and coordination may be an appropriate structural aspect of resilience, the politics of resource use and social relations may lead to very different outcomes, some of which may increase resilience, and others may not.

In the context of engineered water infrastructure, there has been a shift in emphasis toward soft, or green, infrastructure (Schuch et al. 2017). One example is sustainable urban drainage systems, a concept that has been proposed as an innovative way to manage urban stormwater with multiple benefits - reducing the quantity of discharge and thus influencing both flooding and scarcity, permeable surfaces, and storage and pollution management through "natural" wetlands (White 2010). Green infrastructure also helps capture precipitation in addition to runoff (Brown 2014). In flood risk management, authors have argued for a shift away from thinking of floods as caused by natural sources that are external to the city (e.g., river overflows, coastal floods) to encompassing a wider set of sources that are not so easily identified, such as surface water floods (Salinas Rodriguez et al. 2014). In relation to water scarcity, supply-side solutions (e.g., new infrastructure, desalination of saltwater or brackish water, reuse of wastewater, groundwater recharge) are proving insufficient to deal with emerging risks. As such, there has been a stronger push to implement demand-side approaches (e.g., conservation, cutting water losses in transportation and distribution systems, implementing tariff systems). Use of recycled water is an emerging idea (e.g., Attwater and Derry 2017), although it remains widely debated due to concerns about social acceptance and public safety (Watson et al. 2017).

In sum, the large number of propositions that are captured in the diverse body of work on water resilience tend to be highly complex and lacking in coherence. This leads to a lack of clarity and guidance on which practices and actions can actually increase the resilience of various water systems. Rodina $(2019 a, b)$ further 
observed the marked persistence of disciplinary divides stemming from the different traditions in the resilience scholarship, also evident in the vast diversity of framings and propositions seen in the literature. At the same time, in light of looming uncertainty about future hydrological variability, many authors now increasingly argue for integrative and holistic approaches to water management that are better able to address complex interdependencies (Baker et al. 2009, Cosens and Stow 2014, PahlWostl 2015). This includes encompassing the various dimensions of the water cycle, such as green water (i.e., water in vegetation and soil moisture) and blue water (i.e., freshwater in lakes, streams, etc. [see Rockström et al. 2014b]), and addressing the complex multistressor nature of water security challenges, including population growth, aging infrastructure, pollution, land use change, and others (Cosgrove and Loucks 2015). Such holistic approaches are in contrast to the more conventional water management paradigm that has focused largely on isolated or compartmentalized parts of the water cycle, which adds another level of complexity in our understanding of the practical actions and approaches that can help enhance the resilience of water systems. To this end, we investigate the extent to which divergent traditions in the resilience scholarship might preclude more integrative thinking, and the range of water resource management strategies that are considered most important for achieving water resilience, broadly defined.

\section{METHODS}

This research was conducted under the approval of the University of British Columbia's Behavioural Research Ethics Board. The survey data we report were collected through a web-based survey hosted by Fluid Surveys, licensed to the University of British Columbia and compliant with the British Columbia Freedom of Information and Protection of Privacy Act. The survey was piloted with several experts on resilient water governance and was conducted online from June to October 2017. The survey design was informed by data collected for a systematic scoping review that is documented in a separate manuscript (Rodina 2019b). At the time of this research, there had not been another comprehensive study or synthesis that compiled the range of resilience-building strategies for various water sectors. As a result, part of the objective of this survey was to capture the range of strategies that have been identified or suggested in the published academic literature. To this end, we used data that were collected as part of the initial phase of a systematic scoping review on water resilience (Rodina 2019b). Specifically, data were gathered from the Web of Science bibliographic search of academic publications published between 1950 and 2016, using the keywords resilien* (which captured resilience, resilient, and resiliency), and one or more of the following water-related search terms: watershed, drought, flood, water, sanitation, river, stormwater, graywater, drainage, wastewater, hydrology, and freshwater. We used an iterative method to compile as comprehensive a list of search terms as possible (see Rodina $2019 b$ and Appendix 1 for full details on the search strategy).

We reviewed a random sample of 100 abstracts from the nearly 7000 initial search results to identify strategies. Specifically, we looked for mentions of specific water resource management actions and governance arrangements, which we then compiled into a list. The derived strategies were then grouped by similarity (i.e., whether they related to flood management, drought management, or freshwater management) and reduced to a smaller number that were included in the survey. In the survey, participants were asked to rate a series of water resource management and governance strategies that have been identified as potentially important to increasing resilience in water systems. While this method may not have captured all the water resilience strategies mentioned in the literature, in part because much of the literature is ambiguous or lacking specificity on the practices needed to increase water resilience (see more on this in Rodina $2019 b$ ), it provided a good starting point to explore the most prominent ones. In the survey, the strategies were grouped into four categories: (1) general strategies for building resilience in the water sector, (2) strategies for drought resilience, (3) strategies for flood resilience, and (4) strategies for building resilience in freshwater systems (i.e., eco-hydrological systems). These categories represented the most common themes within the broader water resilience literature.

As we discussed earlier, there are multiple and diverse ways to define resilience. In order to examine whether different ways of conceptualizing resilience might be associated with different favored strategies, we offered the survey participants a choice of three conventional and distinctive definitions (adopted from Brand and Jax [2007] and Baggio et al. [2014]). Namely:

a) engineering resilience: the time it takes a system to return to normal after a disturbance

b) ecological resilience: the capacity of a system to absorb shocks without changing states

c) community resilience: the ability of communities or society to cope, adapt, or transform in the face of change

We excluded more complex definitions solely for the purposes of analysis because we wanted to capture the effect of distinctively different conceptualizations of resilience. We also offered the opportunity to add open-ended responses in all parts of the survey, including survey questions related to the governance and equity dimensions of increasing resilience, which will be analyzed and presented separately.

\section{Sampling strategy}

We sought to reach a broad range of water experts, including water planners, engineers, policy-makers, and researchers who have familiarity with resilience as a theory or concept. We were interested in identifying the ways resilience thinking can be applied in the context of water resource management, not necessarily based on specific predetermined definitions of "water resilience" but in a broader sense, including intuitive senses of what water resilience might mean. To identify potential participants, we used data from the initial stage of the systematic scoping review documented in Rodina (2019b). From the bibliographic data, we identified 6700 authors (specifically lead authors), who were invited to participate in the survey by using the contact information provided in the publications. In total, 5816 authors received the survey (nearly 1000 contacts bounced, which is not surprising considering the temporal range of the scholarly search and the fact that authors may no longer be using older email addresses). In total, 536 surveys were filled out (response rate $=9.2 \%$ ), of which 420 were used in the analysis (those that were completed in full). While the response rate may appear to be small, it should be noted that given that "water 
resilience" is a boundary concept (Brand and Jax 2007) and is not an established field or subdiscipline, and that the water governance domain is diverse and spread over multiple sectors, there is no easily identifiable community of experts that we could contact. As a result, we cast a wide net, which successfully captured more than 400 experts who were familiar with resilience and various aspects of water governance (following the expert elicitation survey of Beaudrie et al. 2013, with modifications as needed). Comments received by email suggested that the response rate was driven by self-perceived expertise at the intersection of water and resilience - that is, recipients who perceived themselves as having that expertise were more likely to fill out the survey.

\section{Analysis}

In total, 420 responses were analyzed using SPSS software (version 24). In addition to descriptive statistics, we conducted principal component analysis (PCA) on the strategy that rated questions from the survey (33 variables in total) using varimax orthogonal rotation, which produced a correlation matrix with $\mathrm{KMO}=0.929$ and a statistically significant Bartlett's test of sphericity $(p<.0005)$. According to Kaiser (1974), both of these measures indicate that the PCA was suitable for these data. The PCA was conducted to reduce the number of variables, specifically the variables pertaining to strategies to build resilience, in order to arrive at a smaller set of variables. Using MANOVA, and follow-up univariate ANOVAs as post-hoc tests, we then analyzed participants' favored strategies for enhancing resilience, using the PCA components as proxies, in relation to participants' favored definitions of resilience.

\section{RESULTS}

\section{Summary and resilience-building strategies}

The analyzed survey responses consisted of mostly male $(65 \%)$, white $(64.7 \%)$ participants between the ages of 35 and 54. A large proportion of the survey participants worked in research positions (81\%), with $91 \%$ stating that research is a significant component of their work. The sample was highly educated, with $83 \%$ having doctoral/PhD degrees (or equivalent), and $79 \%$ indicating that they worked in academia. The survey participants included experts in the fields of stormwater management, disaster risk management, water and sanitation, water resources management, flood management, and water governance. Many participants indicated that they worked in more than one of those fields. Most participants were familiar with resilience (95\%) and applied resilience concepts in their work $(83.6 \%)$, but were also somewhat less confident in its novelty, conceptual, or practical dimensions (Fig. 1). In terms of definitions, nearly half of the participants selected community resilience as their preferred definition (44.5\%), about one-third chose ecological (29.4\%), and a smaller proportion (17\%) selected engineering resilience. A small proportion indicated that none of the definitions resonated with them $(8.7 \%)$.

In the Discussion section, we show summaries of how survey participants scored the different resilience-building strategies in the context of drought, flood, freshwater, and general water resource management. The survey data suggested that despite the diversity of definitions of resilience (and therefore conceptualizations of resilience), there was a potential convergence around specific sets of practices across experts from various water-related fields. Specifically, we found evidence of support for most of the resilience-building strategies as rated by experts from various fields, ranging from water resource management to stormwater management and water governance. Of the general strategies (Fig. 2), restoring healthy ecosystems was overwhelmingly voted the most important strategy for increasing resilience in water systems, followed by dealing with uncertainty, and ability to quickly respond to change. Because the biggest fraction of survey participants favored community resilience as their preferred definition (44.5\%), this suggests that while researchers may be concerned mainly about water resilience as it benefits communities, they nevertheless recognize the crucial role that ecosystems play in achieving it. This finding also supports the increasing trend toward conceptualizing water resilience in relation to social systems (Rodina 2019b).

In terms of the strategies that related specifically to drought resilience, flood resilience, or resilience in freshwater systems, we found the following trends. In the context of drought resilience, diversifying water supply sources was rated the highest in terms of importance, while expanding water supply schemes was the lowest rated strategy overall (Fig. 3). This shows that a larger proportion of people rated water supply expansion (such as building new dams, etc.) as "not at all important" for building resilience to drought. With water recycling and switching to less water-intensive livelihoods rated second and third, respectively, we suspect that "drought resilience" for many of the survey participants was more aligned with the notion of living within the limits of available water resources. Demand management, as opposed to supply-side expansion, thus appears to be more heavily favored for increasing resilience to drought.

In terms of flood resilience, the results showed strongest support for integrated approaches that draw on "soft" solutions (such as green infrastructure as opposed to grey infrastructure) and diversity in response options (Fig. 4). Increasing infrastructure redundancy in flood risk management had less support compared to other strategies for flood resilience, thereby highlighting soft and nonstructural approaches as more prominent.

In the context of freshwater systems, participants characterized resilience as very strongly associated with restoring healthy ecosystems, followed by integrated land use and water planning (Fig. 5). Strict regulation on water withdrawals received less support overall, even though it was still voted by many as somewhat important. Notions of resilience in freshwater systems likely draw on ecological understandings of resilience and highlight ecosystem management for resilience as a key strategy.

\section{PCA and MANOVA results}

The PCA revealed seven components with eigenvalues greater than one, with the first component explaining $33 \%$ of the total variance, while the remaining six explained smaller proportions of the variance (between $3 \%$ and $6 \%$ each). These components, or index variables, demonstrate subsets of resilience-building strategies that were closely related to each other-i.e., they tend to vary together. Overall, the first component explained most of the variance in the data. The top five components were extracted based on the rotated matrix table (Table 1) because they made the most sense conceptually. Together, they explained $53 \%$ of the total variance (Catell 1966, Kaiser 1974).

Based on the factor loadings in the PCA (Table 1), we renamed the components as $\mathrm{C} 1$ : Integrated ecosystem water management, 
Fig. 1. Familiarity and novelty of resilience. The Likert-scale questions are listed on the left. This graph shows that most survey participants were familiar with resilience, and used or applied it in their work. Most participants also found resilience to bring novel approaches; however, slightly fewer participants indicated that they did things differently in practice as a result of applying resilience concepts.

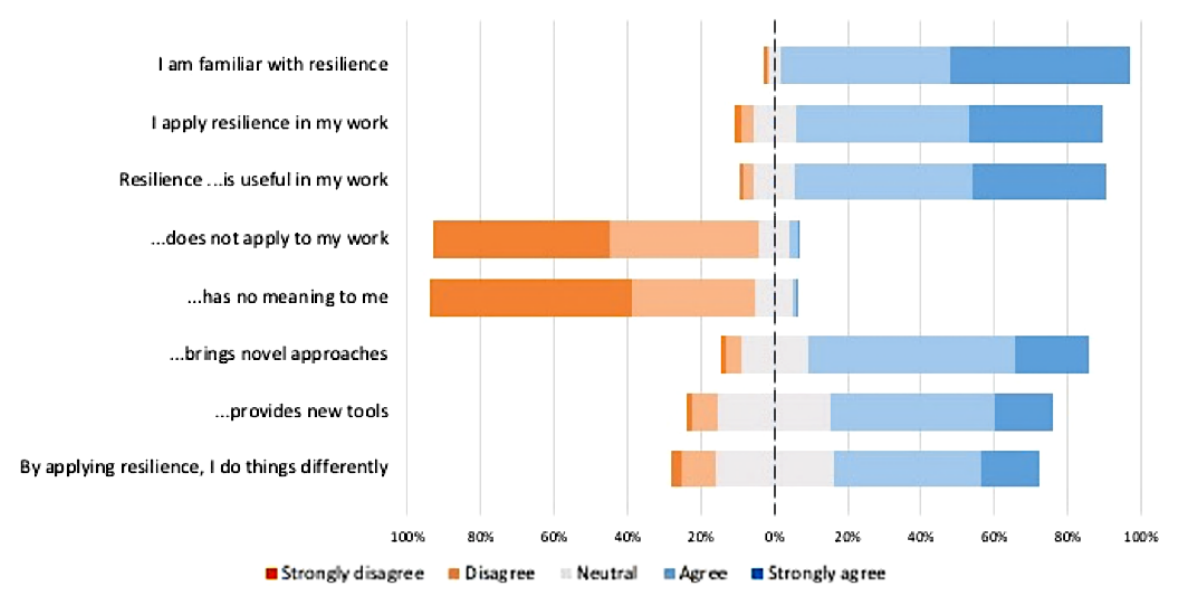

Fig. 2. General water resilience strategies. Survey respondents were asked to rate, on a scale of 1 to 5 , each of the strategies in terms of how important they are for achieving general (or overall) resilience in water governance. While the strategies were randomly ordered on the survey, they are shown here from the highest rated at the top to the lowest rated at the bottom.

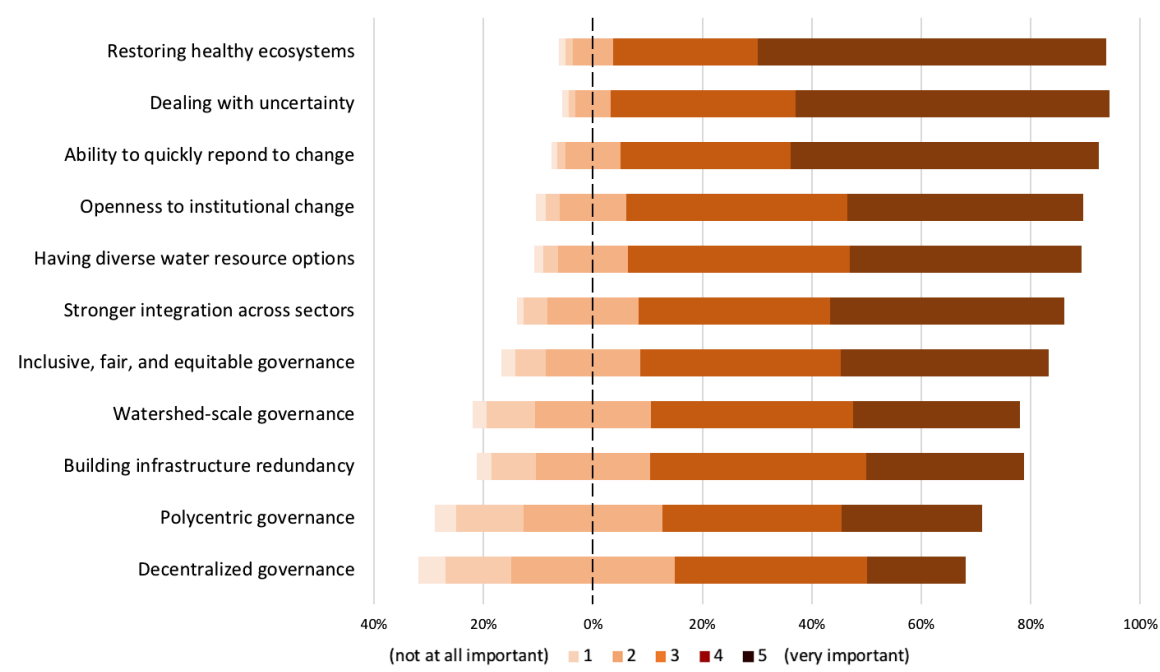

C2: Decentralized water governance, C3: Adaptive water governance, C4: Water supply expansion, and C5: Adaptation to flooding. Details on the variables in each component are included in Table 1. To test whether there was a statistically significant difference in how respondents rated the strategies based on their choice of resilience definition, the five PCA components were analyzed as dependent variables using multivariate analysis of variance (MANOVA) (see Table A1.1 in Appendix 1), with the three main definitions of resilience as independent variables $(p<$ $0.05, n=382$ ). The MANOVA showed statistically significant variation by definition of resilience $(F(10,750)=3.857, p<.0005$; Wilks' $\Lambda=.905$; partial $\eta 2=.049$.). Follow-up univariate ANOVAs (Table 2) showed that this result was driven by two factors, $\mathrm{C} 2$ and $\mathrm{C} 5$, that were significantly different by definition $(p<0.05)$, although the effect sizes were relatively small. Components $\mathrm{C} 1, \mathrm{C} 3$, and $\mathrm{C} 4$ did not vary significantly by definition. Finally, the post-hoc multiple comparison test (Bonferroni) helped identify which components varied significantly by which definitions (see the results discussion for more details, as well as Appendix 1). 
Fig. 3. Strategies that build resilience to drought. Survey respondents were asked to rate, on a scale of 1 to 5 , each of the strategies in terms of how important they are for achieving resilience to drought. While the strategies were randomly ordered on the survey, they are shown here from the highest rated at the top to the lowest rated at the bottom.

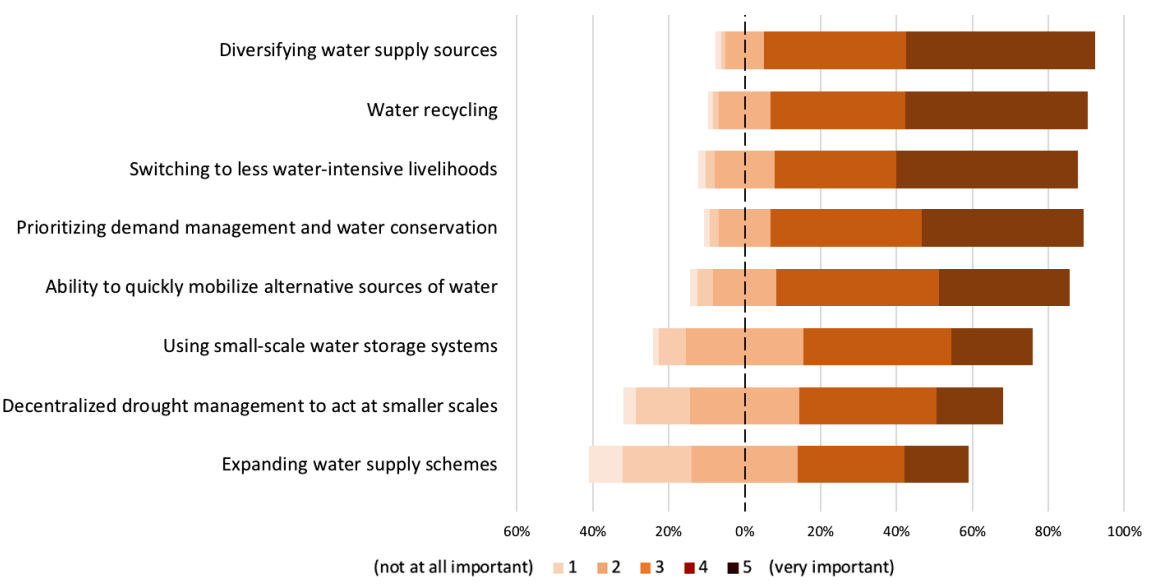

Fig. 4. Strategies that build resilience to flooding. Survey respondents were asked to rate, on a scale of 1 to 5 , each of the strategies in terms of how important they are for achieving resilience to flooding. While the strategies were randomly ordered on the survey, they are shown here from the highest rated at the top to the lowest rated at the bottom.

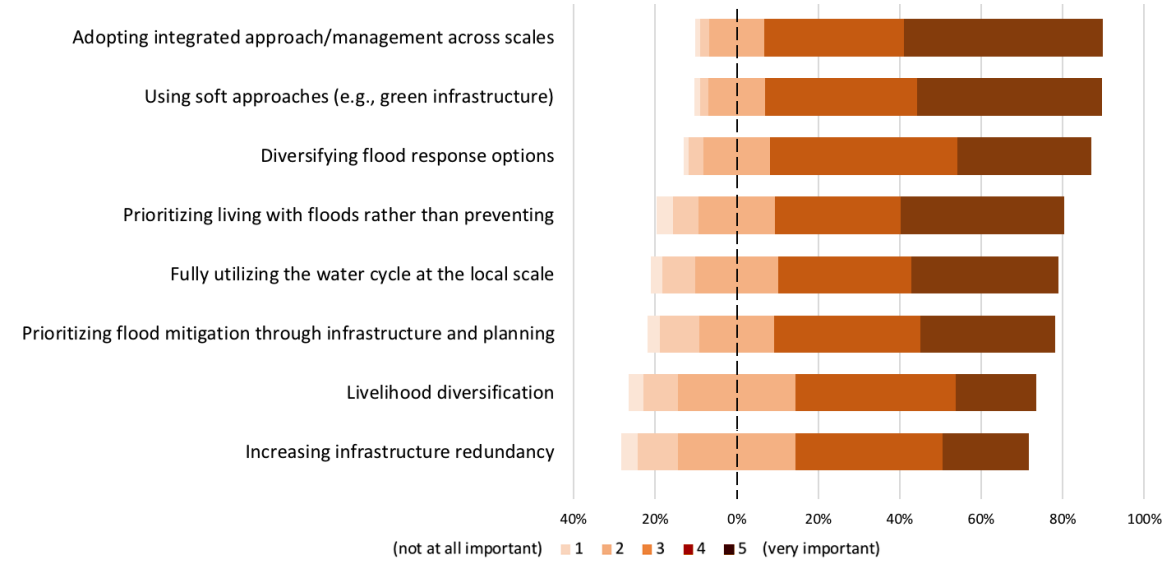

Specifically, the post-hoc test (Bonferroni, shown in Table A1.1 in Appendix 1) showed that people who chose the community resilience definition were more likely to favor C2: Decentralized water governance than those who chose ecological resilience, and much more likely than those who chose the engineering definition. People who chose community resilience were also more likely to favor C5: Adaptation to flooding than those who preferred the engineering definition. Respondents who preferred engineering definitions of resilience were much less likely to favor C5. There was no statistically significant difference for $\mathrm{C} 1$ :Integrated ecosystem water management, C3: Adaptive water governance, and C4: Water supply expansion (see more details in Appendix 1 and Figs. 6 and 7).

\section{DISCUSSION}

Overall, despite the deep disciplinary tensions in the water resilience literature, we found strong support for many strategies across the sample, which suggests convergence around several approaches to building resilience in water systems and water governance. This broad agreement is perhaps surprising given the variation in favored definitions of resilience across the sample, including ecological, engineering, and community definitions. That is, while of course there is variability in favored strategies (as captured by the PCA components), it tends not to be significantly correlated with the ways that participants define resilience (with two exceptions), and therefore is not 
Fig. 5. Strategies that build resilience in freshwater systems. Survey respondents were asked to rate, on a scale of 1 to 5 , each of the strategies in terms of how important they are for achieving resilience in water resource management. While the strategies were randomly ordered on the survey, they are shown here from the highest rated at the top to the lowest rated at the bottom.

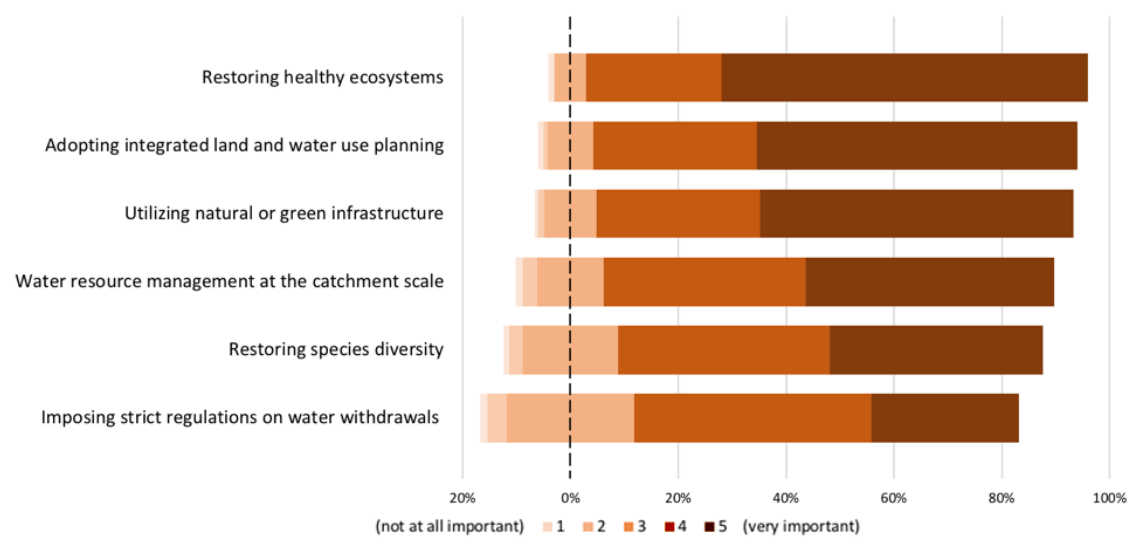

Fig. 6. The variation in favored strategies based on participants' choice of definitions of resilience. C2: Decentralized water governance and C5: Adaptation to floods are significantly different between groups $(p<0.05)$ (see Appendix 1 for more details). The other three components $(\mathrm{C} 1, \mathrm{C} 3$, and $\mathrm{C} 4)$ did not vary significantly by definition. Note: the estimated marginal mean refers to the mean response for each factor adjusted for any other variables in the model.

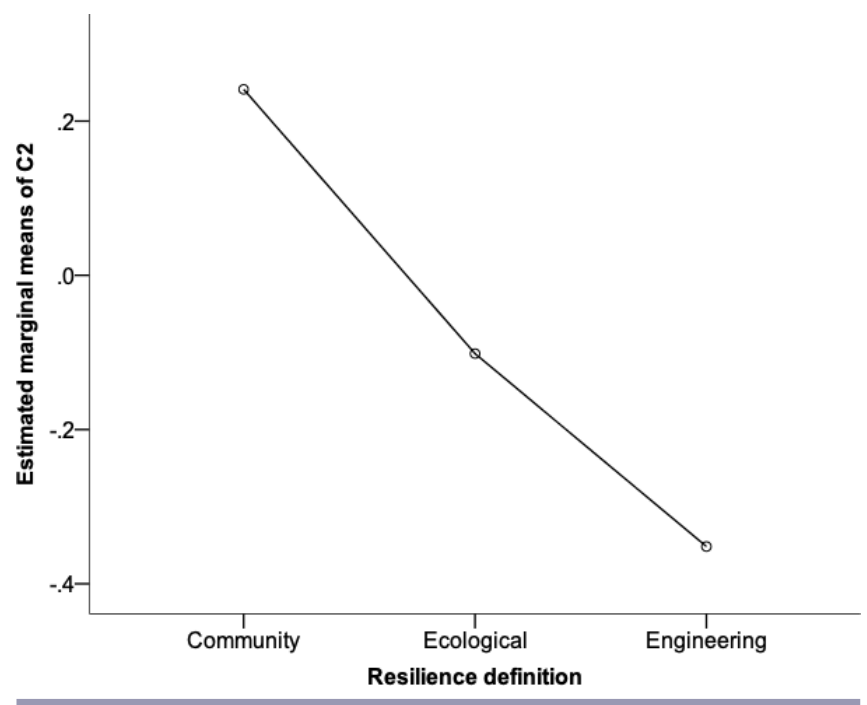

significantly correlated with different disciplinary traditions in the resilience scholarship. In many respects, this is encouraging: despite a tendency among experts to focus on one subsystem or another (ecological, engineered, or social), likely driven by deeply rooted disciplinary divides in the resilience scholarship, there appears to be sufficient overlap in that diverse experts broadly agree on how to build water resilience in complex socio-ecotechnical systems.
Fig. 7. The variation in favored strategies based on participants' choice of definitions of resilience. C2: Decentralized water governance and C5: Adaptation to floods are significantly different between groups $(p<0.05)$ (see Appendix 1 for more details). The other three components $(\mathrm{C} 1, \mathrm{C} 3$, and $\mathrm{C} 4)$ did not vary significantly by definition. Note: the estimated marginal mean refers to the mean response for each factor adjusted for any other variables in the model.

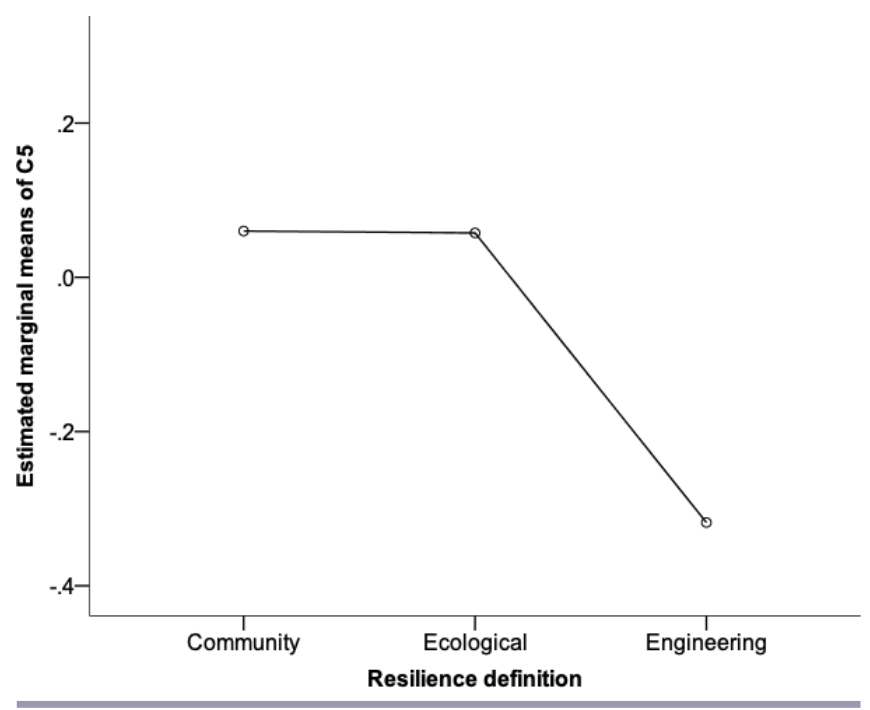

Our study further sheds light on the rather limited understanding we have of the range of approaches that are needed to enhance resilience in various water systems. Interestingly, experts across the spectrum scored most of the strategies as very important, thus indicating a virtual consensus that many strategies and actions are needed to enhance resilience to floods and drought, and in freshwater systems (refer to Figs. 3 to 5). In other words, there is 
Table 1. PCA rotated component matrix. This table shows which variables were included in each component $(\mathrm{C} 1-5)$. On the left-hand side are the strategies. In brackets are the categories they were included under: general strategies for building resilience in the water sector, strategies for drought resilience, flood resilience, and resilience in freshwater systems (i.e., eco-hydrological systems). Only loadings above 0.30 are shown. The 0.30 cut-off threshold was used as recommended by Laerd Statistics (2015). Note: the negative loading in $\mathrm{C} 4$ (see bottom of table) implies a negative relationship between the variable and the component, indicating that respondents who highly rated the other variables in this component were not likely to rate "Prioritizing learning with floods" high. All the other loadings are positively correlated.

\begin{tabular}{|c|c|c|c|c|c|}
\hline \multirow[t]{2}{*}{ Variables } & \multicolumn{5}{|c|}{ Component } \\
\hline & $\mathrm{C} 1$ & $\mathrm{C} 2$ & $\mathrm{C} 3$ & $\mathrm{C} 4$ & $\mathrm{C} 5$ \\
\hline (freshwater) Restoring and maintaining healthy ecosystems & .74 & & & & \\
\hline (freshwater) Implementing water resources management at the catchment scale & .70 & & & & \\
\hline (freshwater) Adopting integrated land and water use planning & .68 & & & & \\
\hline (general) Rescaling governance from the local scale to the watershed or catchment scale & .67 & & & & \\
\hline (freshwater) Utilizing natural or "green" infrastructure (such as wetlands, streams, rivers) & .65 & & & & \\
\hline (general) Restoring and maintaining healthy ecosystems & .63 & & .42 & & \\
\hline (flood) Using "soft" or nonstructural approaches, such as "green" infrastructure, flexible options & .62 & .33 & & & .34 \\
\hline (freshwater) Restoring, protecting, or enhancing species diversity & .58 & & & & \\
\hline (flood) Adopting an integrated approach to manage water across different scales & .56 & .34 & & & \\
\hline (general) Strong integration of different water sectors (e.g., wastewater, bulk water, sanitation) & .56 & & & & \\
\hline (drought) Water recycling & .53 & & & .36 & \\
\hline (freshwater) Imposing strict regulations on water withdrawals & .50 & & .37 & & \\
\hline (drought) Prioritizing demand management and water conservation & .50 & & & & \\
\hline (drought) Adapting by switching to less water-intensive livelihoods & .47 & & & & \\
\hline (general) Redistributing functions, power, and authority from national to provincial and municipal levels of government & & .72 & & & \\
\hline (general) Polycentric governance (i.e., management or governance systems that have multiple centers of authority at different scales) & & .67 & & & \\
\hline (flood) Livelihood diversification & & .64 & & & \\
\hline (drought) Decentralizing drought management approach, with authority to act at smaller scales & & .63 & & .35 & \\
\hline (flood) Fully utilizing the water cycle at the local scale (e.g., stormwater capture and reuse, use of treated wastewater) & .49 & .50 & & & \\
\hline (flood) Diversifying response options & & .47 & & & .45 \\
\hline (general) Inclusive, fair, and equitable governance & .38 & .45 & & & \\
\hline (general) Ability to quickly respond to changes, and to reorganize and adapt & & & .63 & & \\
\hline (drought) Increasing ability to quickly mobilize alternative sources of water & & & .63 & .41 & \\
\hline (general) Acknowledging and dealing with uncertainty in the variability of the water cycle & .35 & & .56 & & \\
\hline (drought) Diversifying sources of water supply & & & .56 & .38 & \\
\hline (general) Having diverse water resource options & & & .56 & & .34 \\
\hline (general) Openness to institutional change & .34 & .35 & .50 & & \\
\hline (drought) Using small-scale water storage systems & & .36 & .36 & .31 & \\
\hline (drought) Expanding water supply schemes (dams, tap into groundwater) & & & & .74 & \\
\hline (flood) Prioritizing flood mitigation through infrastructure and planning & & & & .64 & \\
\hline (flood) Increasing infrastructure redundancy & & & & .42 & .68 \\
\hline (general) Building redundancy in infrastructure systems & & & & & .65 \\
\hline (flood) Prioritizing learning to live with floods, rather than trying to prevent them & & & & -.34 & .54 \\
\hline
\end{tabular}

Extraction method: principal component analysis.

Rotation method: varimax with Kaiser normalization. Rotation converged in 11 iterations.

an implicit notion that water systems, social and biophysical, are not resilient in the face of current and emerging stressors, and that much more needs to be done. As many cities and countries across the world are facing increasing water shortages (for example, South Africa and Australia), the tensions between supply-side and demand-side approaches continue. We shed light on experts' notions of which of these two approaches is more likely to actually increase resilience to droughts. Specifically, according to the survey participants, in the context of water security and drought management, building resilience is primarily about diversifying water supply sources through more holistic management of water, and not necessarily building more dams or expanding surface water supply schemes. Overall, highly rated strategies, such as water recycling, stormwater capture and reuse, and other forms of supply augmentation that utilize various aspects of the water cycle are an indicator of a shift away from reliance solely on surface or blue-water-centered supply paradigms (e.g., Falkenmark and Rockström, 2010). Further, the strategy scores seem to imply experts' focus on adaptation to flooding or drought rather than mitigation of these risks, which suggests an acknowledgement and indeed an acceptance of changing hydrological processes and the need to adapt to new and uncertain water futures.

The MANOVA analysis and the Bonferroni post-hoc test indicated that while there were axes of variation in the strategy scores (as captured by the PCA components), only two of the five components were correlated with participants' choice of resilience definition, with small effect sizes. More specifically, as the PCA showed, the component we termed integrated ecosystem water management captured the largest cluster of variables that vary together (Table 1). This component (C1) encompassed a range of strategies centered on restoring ecosystem health and catchmentlevel management, thereby highlighting the hydrological services provided by wetlands, streams, rivers, and species diversity. Based on the deep-rooted disciplinary divides we discussed earlier, we might expect these differences to be associated with different understandings of resilience. For example, we might suspect researchers who aligned with the community definition of 
Table 2. Follow-up univariate one-way ANOVA results. The relationship between the PCA components and the three resilience definitions was tested. The overall MANOVA test results show that the difference between groups was significant $(F(10,750)=3.857, p<.0005$; Wilks" $\Lambda=.905$; partial $\eta 2=.049$.) The sample size was 382 .

\begin{tabular}{|c|c|c|c|c|c|c|}
\hline Independent variable & Dependent variable & $F$ & $\mathrm{df}$ & Error df & $p$ & $\begin{array}{c}\text { Partial Eta } \\
\text { squared }\end{array}$ \\
\hline \multirow[t]{5}{*}{ Resilience definition } & $\mathrm{C} 1$ : Integrated ecosystem water management & 2.302 & 2 & 379 & .101 & .012 \\
\hline & C2: Decentralized water governance & 11.930 & 2 & 379 & $.000^{*}$ & .059 \\
\hline & C3: Adaptive water governance & .499 & 2 & 379 & .608 & .003 \\
\hline & C4: Water supply expansion & .958 & 2 & 379 & .385 & .005 \\
\hline & C5: Adaptation to flooding & 3.772 & 2 & 379 & $.024 *$ & .020 \\
\hline
\end{tabular}

resilience to have favored community-oriented strategies more strongly and not to have favored ecological or other strategies. The MANOVA results, however, suggest that differences in strategies were not explained mainly by the different disciplinary traditions in resilience thinking. The multiple comparison showed that there was no statistically significant difference in this component $(\mathrm{C} 1)$ based on respondents' choice of definition. Although support for integrated ecosystem water management varied, it is likely a cross-cutting theme that is independent of specific traditions in resilience thinking.

The second component (C2) centered around the idea of decentralized and polycentric governance (these were the two highest-loading or most important variables in this component). The decentralized water governance theme reflects the tendency of participants to give similar ratings to strategies such as decentralization, polycentric governance, and livelihood diversification, as well as diversifying response options to flood risks (Table 1). In other words, C2 captured experts' assessment of the importance of building adaptive capacity to flooding or drought at multiple scales. In contrast to $\mathrm{C} 1, \mathrm{C} 2$ varied significantly by resilience definition. Respondents who selected the community resilience definition were more likely to favor this cluster of strategies - much more so than those who preferred the engineering definition of resilience. Interestingly, equitable governance loaded highest on this component, likely because it was driven by experts' concerns with the governance dimensions of resilience. This component was also heavily focused on governance, and appeared to reflect debates around centralized versus decentralized, or polycentric, governance as key for achieving resilience.

The third component (C3) was very much associated with notions of adaptive water governance. Here, the key strategies were the ability to quickly respond to change, the ability to adapt to uncertainty and variability in the water cycle, and openness to institutional change. As with the first component, support for adaptive water governance did not vary significantly with respondents' favored definitions of resilience. Although there was variation in support for adaptive water governance, it seemed disconnected from ideological or epistemological differences in understandings of resilience. The fourth set of strategies (C4), water supply expansion, was heavily centered on expanding water supply and flood mitigation through infrastructure and planning, while the fifth component (C5), adaptation to flooding, was centered on increasing infrastructure redundancy in the context of flood risk, and the idea of normalizing floods and learning to live with them. This fifth component was narrower in focus than the others, very flood-centric, and promoted a range of strategies such as diversification, building in redundancies, and relying on soft or nonstructural approaches. C5, adaptation to flooding, was the only component other than $\mathrm{C} 2$, decentralized water governance, that showed a potential epistemological effect: respondents who chose community resilience were much more likely to favor $\mathrm{C} 5$, while those who aligned with engineering notions of resilience were significantly less likely to favor it.

This evidence suggests, first, that despite the diversity of water fields and resilience orientations, there is overwhelmingly strong support for most of the strategies in this survey, which suggests cross-cutting agreement that most of these strategies are important and are needed to enhance water resilience. This echoes the conclusions of the UN World Water Development Report that most water systems around the world are not resilient to increasing risks (UN World Water 2015). Second, the PCA helped identify the major axes of variation in the support for these strategies. While the MANOVA results suggest that there was some disagreement among experts, as captured by the PCA components, these disagreements were not driven primarily by the different resilience definitions that experts favored. These findings suggest that disciplinary divides may not be barriers to more integrative thinking beyond conventional conceptualizations of water management. The findings also suggest that "water resilience" does work as a boundary concept (Brand and Jax 2007, Baggio et al. 2014, Olsson et al. 2015) in which epistemological or ontological differences can persist without inhibiting more integrative thinking around the practical applications of resilience. Specifically, as Baggio et al. (2014) argue, resilience, with its focus on various systems and forms of knowledge, can connect different groups that are seeking consensus, thereby enabling knowledge sharing and bridging between science and policy. As such, distinctly different communities of knowledge can engage in reconciling and reinterpreting what resilience means across domains (Baggio et al. 2014). Thus, while debates about how to theorize or operationalize resilience in relation to different systems - social or biophysicalmay be unresolved, the difficulties in defining water resilience may not necessarily inhibit theory-bridging or the potential for water resilience to contribute to new integrative ways of governing water resources.

These results indicate that managing for ecosystem health is likely the most important strategy for increased water resilience, consistent with claims by Rockström, Falkenmark, and others who have argued for eco-hydrological approaches to water resilience 
(Rockström et al. 2014b). This implies that ecosystems and the ecohydrological services they provide might be the highest order objective for resilient water systems - not the expansion or improvement of built infrastructure, despite the engineering bias in water systems research overall. In the context of flood resilience, general resilience, and the resilience of freshwater systems, an overwhelming majority of experts also favored integrated management across scales - likely indicating a need to create crosssectoral connections, thereby breaking down silos or scalar barriers, and potentially opening up water governance to more diverse decision-makers and stakeholders (e.g., Krievins et al. 2015). Further, the high scoring of many strategies, such as using natural or green infrastructure, implementing water recycling, and utilizing the full water cycle, aligns with the concepts of Water Sensitive Urban Design and Sustainable Urban Drainage Systems (Wong and Brown 2009, White 2010, Brown 2014). These are emerging approaches that have not been widely implemented yet but were highly supported by many experts in the sample. These insights suggest that "water resilience" as a paradigm in water governance is more closely associated with the bridging of the various dimensions of the water sector toward a more ecocentric, holistic, and adaptive approach to managing water "along the cycle."

This research is among the early attempts to characterize the building of water resilience in a holistic and integrative way. One of the limitations of this research is related to the small effect sizes mentioned earlier, and the fact that variability persists in experts' perceptions of the importance of different water resilienceenhancing strategies and approaches, which suggests the need for future work to shed more light on the drivers of these differences. Future water research agendas could focus on building the empirical base in support of different emerging strategies and building more understanding of the potential trade-offs that might be involved. In addition, the survey design focused on experts who explicitly relate their work to the concept of resilience. As a result, experts who work with cognate terms or related domains that do not explicitly use the concept of resilience were not included. Future research may capture resilience in a broader sense, and thus encompass more diverse approaches to resilience in different domains. In this study we focused on the perspectives of scholarly experts and may not have captured nonacademic communities of practice. It would be valuable for future research to investigate the applied perspectives of practitioners and other actors who are involved in building water resilience but who do not publish in peer-reviewed journals. Overall, the results of this study suggest that there is a great need for better understanding the applied and practical dimensions of building resilience in the water domain.

\section{CONCLUSION}

We have contributed to a knowledge synthesis of what experts believe to be the most important strategies for increasing resilience in water systems. To this end, experts rated various types of resilience-building strategies. We tested the relationship between these ratings and experts' preference for different disciplinary definitions of resilience (namely, engineering, ecology, and social systems notions of resilience). The evidence suggests that while there are differences in how experts rated different resiliencebuilding strategies, the differences are not strongly linked to how resilience is defined. Overall, the strategy ratings show strong support among experts across diverse sectors and water-related fields for several key strategies. First, managing for ecosystem health is the most important strategy for increased water resilience, as well as integrated management across scales. Further, in the context of water security and drought management, building resilience likely means diversifying water supply sources through more holistic water management by incorporating water recycling, stormwater capture and reuse, etc. The scoring results also suggest that resilience in water systems is strongly associated with adaptation to flooding or drought. As such, "water resilience" implies acknowledgement and indeed an acceptance of changing hydrological processes and the need to adapt to new and uncertain water futures. Overall, this research supports the idea that water resilience serves as a boundary concept that can bind together distinctly different communities of knowledge and practice. It enables these communities to think through integrative cross-scalar approaches for building a more water resilient future for both communities and ecosystems. We have also provided a starting point to synthesize the most prominent water resource management strategies, across sectors, that are likely to contribute to increased resilience of water systems.

Responses to this article can be read online at: http://www.ecologyandsociety.org/issues/responses. $\mathrm{php} / 11302$

\section{Acknowledgments:}

This research was made possible by funding from the Social Science and Humanities Research Council of Canada, as well as the University of British Columbia (Peter Wall Institute for Advanced Studies and Liu Institute for Global Issues). This research benefited from valuable feedback from Drs. Leila Harris and Stephanie Chang, the EDGES research collaborative, and the Program on Water Governance at the University of British Columbia. We are deeply grateful to several colleagues for valuable insights on the survey design, including, but not limited to, Drs. Kieran Findlater, Christian E. H. Beaudrie, Julia Baird, and Gina Ziervogel. We also benefited greatly from the insightful comments of the anonymous reviewers.

\section{LITERATURE CITED}

Attwater, R., and C. Derry. 2017. Achieving resilience through water recycling in peri-urban agriculture. Water 9(3):223. http:// doi.org/10.3390/w9030223

Baggio, J. A., K. Brown, and D. Hellenbrandt. 2014. Boundary object or bridging concept? A citation network analysis of resilience. Ecology and Society 20(2):2. https://doi.org/10.5751/ ES-07484-200202

Baker, L., P. Shanahan, and J. Holway. 2009. Principles for managing the urban water environment in the 21 st century. Pages 275-289 in L. Baker, editor. The water environment of cities. Springer, Boston, Massachusetts, USA. https://doi.

org/10.1007/978-0-387-84891-4 14

Bakker, K., and D. Cameron. 2005. Governance, business models and restructuring water supply utilities: recent developments in Ontario, Canada. Water Policy 7(5):485-508. https://doi. org/10.2166/wp.2005.0029 
Bakker, K., and C. Morinville. 2013. The governance dimensions of water security: a review. Philosophical Transactions of the Royal Society A: Mathematical, Physical and Engineering Sciences 371 (2002):20130116-20130116. https://doi.org/10.1098/rsta.2013.0116

Beaudrie, C. E. H., T. Satterfield, M. Kandlikar, and B. H. Harthorn. 2013. Expert views on regulatory preparedness for managing the risks of nanotechnologies. Plos One 8(11):e80250-9. http://doi.org/10.1371/journal.pone.0080250

Bell, S. 2015. Renegotiating urban water. Progress in Planning 96:1-28. http://doi.org/10.1016/j.progress.2013.09.001

Bell, S., A. Allen, P. Hofmann, and T.-H. Teh, editors. 2017. Urban water trajectories. Springer.

Berkes, F., J. Colding, and C. Folke, editors. 2012. Navigating social-ecological systems. Cambridge University Press, West Nyack, New York, USA.

Biswas, A. 2009. Integrated water resources management: a reassessment. Water International 29(2):248-256. https://doi. org/10.1080/02508060408691775

Brand, F. S., and K. Jax. 2007. Focusing the meaning(s) of resilience: resilience as a descriptive concept and a boundary object. Ecology and Society 12(1):23. https://doi.org/10.5751/ ES-02029-120123

Brown, H. 2014. Next generation infrastructure: principles for postindustrial public works. Springer.

Brown, R. R., N. Keath, and T. H. F. Wong. 2009. Urban water management in cities: historical, current and future regimes. Water Science \& Technology 59(5):847-855. http://doi. org/10.2166/wst.2009.029

Cattell, R. B. 1966. The scree test for the number of factors. Multivariate Behavioral Research 1:245-276. https://doi. org/10.1207/s15327906mbr0102 10

Cosens, B. A., and G. A. Stow. 2014. Resilience and water governance: addressing fragmentation and uncertainty in water allocation and water quality law. Pages 142-175 in A. S. Garmestani and C. D. Allen, editors. Social-ecological resilience and law. Columbia University Press, New York, New York, USA. https://doi.org/10.7312/garm16058-007

Cosens, B. A., and A. Williams. 2012. Resilience and water governance: adaptive governance in the Columbia River Basin. Ecology and Society 17(4):3.

Cosgrove, W. J., and D. P. Loucks. 2015. Water management: current and future challenges and research directions. Water Resources Research 51(6):4823-4839. http://doi.org/10.1002/2014WR016869

D’Odorico, P., F. Laio, and L. Ridolfi. 2010. Does globalization of water reduce societal resilience to drought? Geophysical Research Letters 37(13):L13403. https://doi.org/10.1029/2010GL043167

Dunn, G., R. R. Brown, J. J. Bos, and K. Bakker. 2016. Standing on the shoulders of giants: understanding changes in urban water practice through the lens of complexity science. Urban Water Journal 14(7):758-767. http://doi.org/10.1080/1573062X.2016.1241284

Dunn, G., L. Harris, and K. Bakker. 2017. Canadian drinking water policy: jurisdictional variation in the context of decentralized water governance. Pages 301-320 in S. Renzetti and D. P. Dupont, editors. Water policy and governance in Canada. Springer International Publishing. https://doi.org/10.1007/978-3-319-42806-2_16

Falkenmark, M., and J. Rockstrom. 2010. Building water resilience in the face of global change: from a blue-only to a greenblue water approach to land-water management. Journal of Water Resources Planning and Management 136(6):606-610. https://doi. org/10.1061/(ASCE)WR.1943-5452.0000118

Ferguson, B., R. R. Brown, and A. Deletic. 2013. Diagnosing transformative change in urban water systems: theories and frameworks. Global Environmental Change 23(1):264-280. https:// doi.org/10.1016/j.gloenvcha.2012.07.008

Folke, C. 2016. Resilience (republished). Ecology and Society 21 (4):44. http://doi.org/doi:10.5751/ES-09088-210444

Fowler, H. J., C. G. Kilsby, and P. E. O’Connell. 2003. Modeling the impacts of climatic change and variability on the reliability, resilience, and vulnerability of a water resource system. Water Resources Research 39(8):1222.

Galaz, V. 2005. Social-ecological resilience and social conflict: institutions and strategic adaptation in Swedish water management. Ambio 34(7):567-572. http://doi.org/10.1579/0044$-7447-34.7 .567$

Green, O. O., B. A. Cosens, and A. S. Garmestani. 2013. Resilience in transboundary water governance: the Okavango River Basin. Ecology and Society 18(2):23. http://doi.org/10.5751/ ES-05453-180223

Gunderson, L. H., S. R. Carpenter, C. Folke, P. Olsson, and G. D. Peterson. 2006. Water RATs (resilience, adaptability, and transformability) in lake and wetland social-ecological systems. Ecology and Society 11(1):16. https://doi.org/10.5751/ES-01556-110116

Huitema, D., E. Mostert, W. Egas, S. Moellenkamp, C. PahlWostl, and R. Yalcin. 2009. Adaptive water governance: assessing the institutional prescriptions of adaptive (co-)management from a governance perspective and defining a research agenda. Ecology and Society 14(1):26. https://doi.org/10.5751/ES-02827-140126

Huntjens, P., L. Lebel, C. Pahl-Wostl, J. Camkin, R. Schulze, and K. Nicole. 2012. Institutional design propositions for the governance of adaptation to climate change in the water sector. Global Environmental Change 22(1):67-81. http://doi.org/10.1016/ j.gloenvcha.2011.09.015

Jabareen, Y. 2013. Planning the resilient city: concepts and strategies for coping with climate change and environmental risk. Cities 31(April 2013):220-229. http://doi.org/10.1016/j.cities.2012.05.004

Johannessen, A., and C. Wamsler. 2017. What does resilience mean for urban water services? Ecology and Society 22(1):1. http:// doi.org/doi:10.5751/ES-08870-220101

Kaiser, H. F. 1974. An index of factorial simplicity. Psychometrika 39(1):31-36. https://doi.org/10.1007/BF02291575

Krievins, K., J. Baird, R. Plummer, O. M. Brandes, A. Curry, J. Imhof, S. Mitchell, M.-L. Moore, and ^ G. Swartling. 2015. Resilience in a watershed governance context: a primer. Environmental Sustainability Research Centre, St. Catharines, Ontario, Canada. 
Laerd Statistics. 2015. Principal components analysis (PCA) using SPSS statistics. Statistical tutorials and software guides.

Milly, P. C. D., J. Betancourt, M. Falkenmark, R. M. Hirsch, Z. W. Kundzewicz, D. P. Lettenmaier, and R. J. Stouffer. 2008. Stationarity is dead: whither water management? Science 319 (5863):573-574. http://doi.org/10.1126/science.1151915

Olsson, L., A. Jerneck, H. Thorén, J. Persson, and D. O'Byrne. 2015. Why resilience is unappealing to social science: theoretical and empirical investigations of the scientific use of resilience. Science Advances 1(4):e1400217-e1400217. http://doi.org/10.1126/ sciadv. 1400217

Pahl-Wostl, C. 2015. Water policy-from panaceas towards embracing complexity. Pages 11-24 in Water governance in the face of global change: from understanding to transformation. Springer International Publishing. http://doi.org/10.1007/978-3$-319-21855-7 \quad 2$

Pahl-Wostl, C., G. Holtz, B. Kastens, and C. Knieper. 2010. Analyzing complex water governance regimes: the management and transition framework. Environmental Science \& Policy 13 (7):571-581. http://doi.org/10.1016/j.envsci.2010.08.006

Pahl-Wostl, C., and C. Knieper. 2014. The capacity of water governance to deal with the climate change adaptation challenge: using fuzzy set Qualitative Comparative Analysis to distinguish between polycentric, fragmented and centralized regimes. Global Environmental Change 29:139-154. http://doi.org/10.1016/j. gloenvcha.2014.09.003

Pahl-Wostl, C., L. Lebel, C. Knieper, and E. Nikitina. 2012. From applying panaceas to mastering complexity: toward adaptive water governance in river basins. Environmental Science \& Policy 23(2012):24-43.

Rijke, J., M. Farrelly, R. R. Brown, and C. Zevenbergen. 2013. Configuring transformative governance to enhance resilient urban water systems. Environmental Science \& Policy 25 (2013):62-72. https://doi.org/10.1016/j.envsci.2012.09.012

Rockstrom, J., M. Falkenmark, T. Allan, C. Folke, L. A. Gordon, and A. Jägerskog. 2014a. The unfolding water drama in the Anthropocene: towards a resilience-based perspective on water for global sustainability. Ecohydrology 7(5):1249-1261. http://doi. org/10.1002/eco.1562

Rockstrom, J., M. Falkenmark, C. Folke, M. Lannerstad, J. Barron, E. Enfors, et al. 2014b. Water resilience for human prosperity. Cambridge University Press.

Rodina, L. 2019a. Planning for water resilience: competing agendas among Cape Town's planners and water managers. Environmental Science \& Policy 99:10-16. http://doi.org/10.1016/ j.envsci.2019.05.016

Rodina, L. 2019b. Defining "water resilience": debates, concepts, approaches, and gaps. Wiley Interdisciplinary Reviews: Water 6 (2):1-18. http://doi.org/10.1002/wat2.1334

Salinas Rodriguez, C. N. A., R. Ashley, B. Gersonius, J. Rijke, A. Pathirana, and C. Zevenbergen. 2014. Incorporation and application of resilience in the context of water-sensitive urban design: linking European and Australian perspectives. Wiley Interdisciplinary Reviews: Water 1(2):173-186. http://doi. org/10.1002/wat2.1017

Schluter, M., and C. Pahl-Wostl. 2007. Mechanisms of resilience in common-pool resource management systems: an agent-based model of water use in a river basin. Ecology and Society 12(2):4. https://doi.org/10.5751/ES-02069-120204

Schuch, G., S. Serrao-Neumann, E. Morgan, and D. L Choy. 2017. Water in the city: green open spaces, land use planning and flood management — an Australian case study. Land Use Policy 63:539-550. https://doi.org/10.1016/j.landusepol.2017.01.042

Shin, S., S. Lee, D. Judi, M. Parvania, E. Goharian, T. McPherson, and S. Burian. 2018. A systematic review of quantitative resilience measures for water infrastructure systems. Water 10(2):164. http://doi.org/10.3390/w10020164

Srinivasan, V., K. C. Seto, R. Emerson, and S. M. Gorelick. 2013. The impact of urbanization on water vulnerability: a coupled human-environment system approach for Chennai, India. Global Environmental Change 23(1):229-239. http://doi.org/10.1016/j. gloenvcha.2012.10.002

Steffen, W., Å. Persson, L. Deutsch, J. Zalasiewicz, M. Williams, et al. 2011. The Anthropocene: from global change to planetary stewardship. Ambio 40(7):739. http://doi.org/10.1007/s13280-011-0185$\underline{x}$

United Nations World Water Assessment Programme (UN World Water). 2015. The United Nations World Water Development Report 2015: water for a sustainable world. UNESCO, Paris, France.

Watson, R., P. Mukheibir, and C. Mitchell. 2017. Local recycled water in Sydney: a policy and regulatory tug-of-war. Journal of Cleaner Production 148:583-594. https://doi.org/10.1016/j. jclepro.2017.01.174

Welch, C. 2018. Why Cape Town is running out of water, and who's next. National Geographic. https://news.nationalgeographic. com/2018/02/cape-town-running-out-of-water-drought-taps-shutoffother-cities/

White, I. 2010. Water and city: risk, resilience and planning for a sustainable future. Routledge, London, UK. https://doi. org/10.4324/9780203848319

Wong, T. H. F., and R. R. Brown. 2009. The water sensitive city: principles for practice. Water Science and Technology 60 (3):673-682. http://doi.org/10.2166/wst.2009.436 


\section{Appendix 1}

\section{Supplementary Survey Results}

Table A1.1 MANOVA and post-hoc tests (Bonferroni). The multiple comparison table shows the two components that showed statistically significant differences in the choices of definitions (C2 and C5), while C1, C3 and C4 do not vary significantly by definition. In sum, people who chose the community resilience definition we more likely to rate C2 higher than those who chose ecological resilience and much more likely than those who chose the engineering definition. People who chose community resilience were also more likely to rate C5 higher than those who preferred the engineering definition. Respondents who preferred engineering definitions of resilience were much less likely to rate C5 high.

\begin{tabular}{|c|c|c|c|c|}
\hline Dependent Variable & (I) resDef & (J) resDef & $\begin{array}{l}\text { Mean } \\
\text { Difference } \\
\text { (I-J) }\end{array}$ & Sig. \\
\hline \multirow{6}{*}{$\begin{array}{l}\mathrm{C} 1 \\
\text { Integrated ecosystem water } \\
\text { management }\end{array}$} & \multirow[t]{2}{*}{ Community } & Ecological & -.064 & 1.000 \\
\hline & & Engineering & -.292 & .098 \\
\hline & \multirow[t]{2}{*}{ Ecological } & Community & .064 & 1.000 \\
\hline & & Engineering & -.228 & .354 \\
\hline & \multirow[t]{2}{*}{ Engineering } & Community & .292 & .098 \\
\hline & & Ecological & .228 & .354 \\
\hline \multirow{6}{*}{$\begin{array}{l}\text { C2 } \\
\text { Decentralized water governance }\end{array}$} & \multirow[t]{2}{*}{ Community } & Ecological & $.343^{*}$ & .004 \\
\hline & & Engineering & $.593^{*}$ & .000 \\
\hline & \multirow[t]{2}{*}{ Ecological } & Community & $-.343^{*}$ & .004 \\
\hline & & Engineering & .250 & .235 \\
\hline & \multirow[t]{2}{*}{ Engineering } & Community & $-.593^{*}$ & .000 \\
\hline & & Ecological & -.250 & .235 \\
\hline \multirow{6}{*}{$\begin{array}{l}\text { C3 } \\
\text { Adaptive water governance }\end{array}$} & \multirow[t]{2}{*}{ Community } & Ecological & -.105 & 1.000 \\
\hline & & Engineering & -.078 & 1.000 \\
\hline & \multirow[t]{2}{*}{ Ecological } & Community & .105 & 1.000 \\
\hline & & Engineering & .027 & 1.000 \\
\hline & \multirow[t]{2}{*}{ Engineering } & Community & .078 & 1.000 \\
\hline & & Ecological & -.027 & 1.000 \\
\hline $\mathrm{C} 4$ & \multirow[t]{2}{*}{ Community } & Ecological & .114 & .913 \\
\hline \multirow[t]{5}{*}{ Water supply expansion } & & Engineering & -.079 & 1.000 \\
\hline & \multirow[t]{2}{*}{ Ecological } & Community & -.114 & .913 \\
\hline & & Engineering & -.194 & .591 \\
\hline & \multirow[t]{2}{*}{ Engineering } & Community & .079 & 1.000 \\
\hline & & Ecological & .194 & .591 \\
\hline C5 & Community & Ecological & .002 & 1.000 \\
\hline \multirow[t]{5}{*}{ Adaptation to flooding } & & Engineering & $.378^{*}$ & .027 \\
\hline & \multirow[t]{2}{*}{ Ecological } & Community & -.002 & 1.000 \\
\hline & & Engineering & $.376^{*}$ & .046 \\
\hline & \multirow[t]{2}{*}{ Engineering } & Community & $-.378^{*}$ & .027 \\
\hline & & Ecological & $-.376^{*}$ & .046 \\
\hline
\end{tabular}




\section{Survey Instrument}

Note: Only part of the data was used for this paper. Other data from this survey is used in a separate manuscript, currently in preparation.

\section{Resilience definitions}

Resilience as a concept is proliferating in many areas of resources management and governance.

Please indicate which definition of resilience resonates THE MOST with you

- Resilience refers to the time it takes a system to return to normal after a disturbance

Resilience is the capacity of a system to absorb a shock without changing states

Resilience is the ability of communities or society to cope with, adapt and transform in the face of change

None of these definitions resonates with me

I am not familiar with this concept

I do not understand resilience well enough to define it

Please also provide your own definition if the suggestions provided above do not sufficiently capture your thoughts on the meaning of resilience (optional)

What specific actions or practices do you think can enhance resilience in the context of water planning or management? (optional)

Further comments or thoughts on resilience (optional)

\section{General attitudes towards resilience}

Please indicate how strongly you agree or disagree with the following statements

$\begin{array}{lccc}\text { Strongly } & \text { Disagree } & \text { Neutral Agree } & \begin{array}{l}\text { Strongly } \\ \text { agree }\end{array}\end{array}$

I am familiar with the concept of

resilience

I apply resilience concepts in my work

Resilience is a useful framework in my line of work 
Resilience, as a concept or a

framework, does not apply to my line

of work

Resilience is just a buzzword and has

no meaning for me

Please provide examples of novel practices or tools, in your line of work, that are inspired or motivated by resilience thinking (optional)

\section{Resilience and novelty}

Please indicate how strongly you agree or disagree with the following statements

$\begin{array}{lcl}\begin{array}{l}\text { Strongly Disagree } \\ \text { disagree }\end{array} & \text { Neutral Agree } & \begin{array}{l}\text { Strongly } \\ \text { agree }\end{array}\end{array}$

Resilience brings novel approaches and ways of thinking to my field of work.

Resilience thinking provides distinctively new tools and practices

By applying resilience thinking, I do things differently in my line of work

$\bigcirc$ 
Rescaling governance from the local scale to the watershed or catchment scale

Strong integration of different water sectors (e.g., wastewater, bulk water, sanitation)

Inclusive, fair and equitable governance

Building redundancy in infrastructure systems

Having diverse water resource options

Restoring and maintaining healthy ecosystems

Acknowledging and dealing with uncertainty in the variability of the water cycle

Please provide comments or specific examples (optional)

\section{Strategies that build resilience to drought}

In the context of dealing with droughts, several strategies have been identified as potentially useful for building resilience. Please indicate how important (or not) you think the following factors would be for achieving resilience to droughts. $1=$ not important at all, $5=$ very important

Diversifying sources of water supply

Using small-scale water storage systems

Increasing ability to quickly mobilize alternative sources of water

Decentralizing drought management approach with authority to act at smaller scales

Prioritizing demand management and water conservation

Adapting by switching to less water intensive livelihoods

Water recycling

Expanding water supply schemes (dams, tap into groundwater)

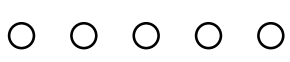

00000

00000

$\circ \circ 0 \bigcirc 0$

00000

0000

00000

00000

\section{Please provide comments or specific examples (optional)}

\section{Strategies that build resilience to floods}

In the context of dealing with floods, several strategies have been identified as potentially useful for building resilience. Please indicate how important (or not) you think the following factors would be for achieving resilience to floods. $1=$ not important at all, $5=$ very important 
Increasing infrastructure redundancy

Prioritizing learning to live with floods, rather than trying to prevent them

Diversifying response options

Livelihood diversification

Using "soft" or non-structural approaches, such as "green" infrastructure, flexible options, etc.

Fully utilizing the water cycle at the local scale (i.e., stormwater capture and reuse; use of treated wastewater, etc)

Adopting an integrated approach to manage water across different scales

Prioritizing flood mitigation through infrastructure and planning

Please provide comments or specific examples (optional)

\section{Strategies that build resilience in freshwater systems}

In the context of management of freshwater resources, several strategies have been identified as potentially useful for building resilience. Please indicate how important (or not) you think the following factors would be for achieving resilience of freshwater systems $1=$ not important at all, $5=$ very important

Restoring and maintaining healthy ecosystems

Utilizing natural or "green" infrastructure" (such as wetlands, streams, rivers)

Restoring, protecting or enhancing species diversity

Imposing strict regulations on water withdrawals

Implementing water resources management at the catchment scale

Adopting integrated land and water use planning

Please provide comments or specific examples (optional)

\section{Governance for resilience}

Please indicate how strongly you agree or disagree with the following statements

$\begin{array}{lccc}\begin{array}{l}\text { Strongly } \\ \text { disagree }\end{array} & \text { Disagree } & \text { Neutral Agree } & \begin{array}{l}\text { Strongly } \\ \text { agree }\end{array}\end{array}$


Building resilience necessitates governance transformation

Building resilience necessitates strengthening of existing governance systems

Governance for resilience necessitates stronger integration across different sectors

Governance for resilience requires a polycentic model (i.e., management or governance systems that have multiple centers of authority at different scales)

O

$\bigcirc$

O

O

$\bigcirc$

$0 \quad 0$

(1)

$\bigcirc \quad \bigcirc$

$0 \quad 0$

0

O

$0 \quad 0 \quad 0 \quad 0$

Resilience and social equity in the water sector

Please indicate how strongly you agree or disagree with the following statements

\begin{tabular}{|c|c|c|c|c|}
\hline $\begin{array}{l}\text { Strongly } \\
\text { disagree }\end{array}$ & Disagree & Neutral & Agree & $\begin{array}{l}\text { Strongly } \\
\text { agree }\end{array}$ \\
\hline
\end{tabular}

While equity is an important societal goal, it is distinctive and unrelated to resilience

There are inherent tradeoffs between equity and resilience

Equity, fairness and participation in governance increase resilience in the water sector

\title{
Social equity increases resilience in the water sector because
} select all that apply

Social equity contributes to a more stable society without social conflict

Achieving any objective in the water sector requires buy-in from everyone

Equitable systems are able to adapt better to changes or disturbances

Social equity does not increase resilience

I am not sure

Other reasons

What role does social equity play in achieving resilience? (optional) 


\section{Demographic information}

In which country/countries is your institution located?

Please select the field(s) that best describe your line of work

Stormwater management

$\square$ Disaster risk management

$\square$ Water and sanitation

$\square$ Water resources management

Flood management

$\square$ Water governance

Other

Please select the sector(s) that you mainly you work in

$\square$ NGO

$\square$ Local government

Provincial government

$\square$ National government

$\square$ Academia

$\square$ Independent consultant

Private sector

$\square$ Other

What is the highest degree level that you have completed?

○ Associate's degree

○ Bachelor's degree

○ Master's degree

○ Doctoral degree

O Other

How would you best describe the type of work you are mostly doing at the moment?

Administrative

$\square$ Engineering

Outreach / communications

$\square$ Program Director/Executive 
$\square$ Policy, governance, and/or regulation

Research

Other

Is conducting research a significant component of your work?

O Yes

○ No

Do you consider yourself:

Hispanic or Latino

Black or African American

Asian or Pacific Islander

Aboriginal

Native American or American Indian

Arab or Middle Eastern

White/Caucasian

Other

$\square$ Prefer not to answer

What is your gender?

O Female

O Male

○ Non-binary

○ Prefer not to answer

O Other

What is your age?

O Less than 25

O 25-34

○ $35-44$

○ $45-54$

○ $55-64$

○ 65 or more

What is your current country of residence/ work? 


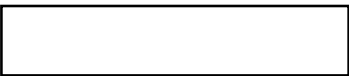

In which country or countries does most of your work take place? 